\title{
Ambulatory and conventional pulse pressures and mean pressures as determinants of the Sokolow-Lyon ECG voltage index in older patients with systolic hypertension Lutgarde Thijs ${ }^{a}$, Eoin T O'Brien ${ }^{b}$ and Jan A Staessen ${ }^{a}$, for the Systolic Hypertension in Europe (Syst-Eur) Trial Investigators
}

\author{
Blood Pressure Monitoring 2001, 6:197-202 \\ Keywords: isolated systolic hypertension, ECG-voltage, ambulatory \\ blood pressure, pulse pressure, mean pressure \\ ${ }^{a}$ Study Coordinating Centre, Hypertension and Cardiovascular \\ Rehabilitation Unit, Department of Molecular and Cardiovascular Research, \\ University of Leuven, Leuven, Belgium and ${ }^{b}$ the Hypertension Unit, \\ Beaumont Hospital, Dublin, Ireland. \\ Correspondence and requests for reprints to Lutgarde Thijs, \\ Studiecoördinatiecentrum, Laboratorium Hypertensie, Campus \\ Gasthuisberg, Herestraat 49, B-3000 Leuven, Belgium. \\ Tel: +32 16345 767; fax: +32 16345763 ; \\ e-mail: Lutgarde.Thijs@med.kuleuven.ac.be \\ A list of Syst-Eur Trial participants is given at the end of the paper.
}

Received 27 August 2001 Accepted 04 September 2001

\section{Introduction}

M-mode echocardiography is considered the gold standard for measuring left ventricular mass [1]. However, this technique is difficult to implement in large multicentre studies because obese and older patients or subjects with pulmonary disorders are often not echogenic, leading to their exclusion [2] and possible bias in the study sample. By contrast, a standard 12-lead ECG can easily be obtained in all subjects. Moreover, several studies have shown that precordial voltages are significantly correlated with echo-determined left ventricular mass. In addition, the sensitivity of ECG detection of left ventricular hypertrophy has been demonstrated to increase with age and may be greater in a population with greater pathological extremes of left ventricular hypertrophy [3].

Observational studies [4-9] and recent overviews, [10,11] all based on the calculation of pulse pressure and mean pressure from conventional blood pressure readings, suggested that in middle-aged and older subjects cardiovascular prognosis gets worse with higher pulse pressure, not mean pressure. Until now, no study addressed the question whether the use of ambulatory pulse pressure or ambulatory mean pressure may further enhance the risk stratification of hypertensive patients.

In this article, we used the baseline ambulatory blood pressure recordings obtained in the Systolic Hypertension in Europe (Syst-Eur) trial [12] to investigate whether ambulatory pulse pressure correlates with the Sokolow-Lyon voltage index independent of the ambulatory mean pressure and independent of the pulse pressure calculated from conventional blood pressure readings.

\section{Methods}

The protocol of the Syst-Eur trial, described elsewhere [13], was approved by the ethics committees of all participating centres. Eligible patients had to be at least 60 years old, and to have when seated a systolic pressure of $160-219 \mathrm{mmHg}$ with diastolic pressure below $95 \mathrm{mmHg}$. These blood pressure criteria rested on the mean of six conventional readings obtained in the sitting position during the placebo run-in period (two readings at three visits one month apart). The present paper only includes baseline data.

Forty-six of 198 Syst-Eur centres opted to enrol their 
patients in the side project on ambulatory measurement [14]. Validated [15] monitors were programmed to obtain measurements at intervals no longer than $30 \mathrm{~min}$ utes. The cuff was secured to the non-dominant arm except if on conventional sphygmomanometry, the difference in systolic pressure between both arms was $10 \mathrm{~mm} \mathrm{Hg}$ or more, in which case the arm giving the highest reading was chosen for all blood pressure measurements. If arm circumference exceeded $31 \mathrm{~cm}$, cuffs with $35 \times 15 \mathrm{~cm}$ bladder were used.

Of 837 randomised patients with a $24 \mathrm{~h}$ recording at entry, $29(3.5 \%)$ were excluded because more than $20 \%$ of the required readings were unavailable. The remaining 808 patients had their baseline recording before randomisation $(n=695)$ or shortly (median 4 months, interquartile range 2-5 months) after randomisation (n $=113$ ). From unedited recordings we computed timeweighted blood pressure means for the whole day, daytime (from 10 a.m. to 8 p.m.) and night time (from midnight to 6 a.m.) [14]. Pulse pressure was defined as systolic minus diastolic blood pressure. Ambulatory mean pressure was measured oscillometrically in 668 patients $(82.7 \%)$. For ambulatory measurements recorded by an auscultatory monitor and for all conventional blood pressure readings, mean pressure was computed as diastolic pressure plus one third of pulse pressure.

A standard 12-lead ECG was obtained following the procedures specified in the Minnesota Code for the standardization of ECG recordings [16]. The voltages of the R-wave in lead $V_{5}\left(R V_{5}\right)$ and the $S$-wave in lead $V_{1}$ $\left(\mathrm{SV}_{1}\right)$ were measured by the local investigator and checked against the original ECG recording at the Coordinating Office. The Sokolow-Lyon voltage index was calculated as the sum of $\mathrm{SV}_{1}$ and $\mathrm{RV}_{5}$ [17].

We based our statistical analysis on two-sided tests, using SAS software version 8.01 (Cary, North Carolina, USA). Means were compared by the standard normal $z$-test and proportions by the $\chi^{2}$ statistic. We used single and multiple linear repression analysis to study the correlates of pulse pressure and the Sokolow-Lyon voltage index. The independent effects of the conventional and ambulatory pulse and mean arterial pressures on left ventricular size was assessed using multiple linear and logistic regression analysis.

\section{Results}

\section{Patients characteristics}

The characteristics of the 311 men and 497 women included in the present analysis were similar to those of the total study population (Table 1). Median age was 69 years (range 60-93). Previous cardiovascular complications were present in 215 patients, of whom 119 had a Sokolow-Lyon voltage index [17] compatible with left ventricular hypertrophy.

Systolic, diastolic, pulse and mean pressures (Table 2) were similar in men and women. Pulse pressure measured in the clinic was on average $19.9 \mathrm{mmHg}$ higher

Table 1 Patient characteristics and ECG voltages

\begin{tabular}{|c|c|c|c|}
\hline & Men & Women & Both sexes \\
\hline $\begin{array}{l}\text { Number of patients } \\
\text { Characteristics }\end{array}$ & 311 & 497 & 808 \\
\hline Age, years & $69.4 \pm 6.1$ & $69.8 \pm 6.3$ & $69.6 \pm 6.2$ \\
\hline Body-mass index, $\mathrm{kg} / \mathrm{m}^{2}$ & $26.1 \pm 3.2$ & $27.0 \pm 4.4^{* * *}$ & $26.7 \pm 4.0$ \\
\hline Conventional heart rate, beats $/ \mathrm{min}$ & $72.4 \pm 9.6$ & $74.1 \pm 8.6^{*}$ & $73.5 \pm 9.0$ \\
\hline Previous antihypertensive medication, $n(\%)$ & $108(34.7 \%)$ & $236(47.5 \%) * * *$ & $344(42.6 \%)$ \\
\hline Cardiovascular complications, $n(\%)$ & $111(35.7 \%)$ & $104(20.9 \%) * * *$ & $215(26.6 \%)$ \\
\hline Current smokers, $n(\%)$ & $46(14.8 \%)$ & $23(4.6 \%) * * *$ & $69(8.5 \%)$ \\
\hline $\begin{array}{l}\geq 1 \text { unit alcohol per day, } n(\%) \\
\text { ECG voltages, } m V\end{array}$ & $82(26.4 \%)$ & $42(8.5 \%) * * *$ & $124(15.3 \%)$ \\
\hline $\mathrm{SV}_{1}$ & $1.01 \pm 0.54$ & $1.02 \pm 0.48$ & $1.02 \pm 0.50$ \\
\hline $\mathrm{RV}_{5}$ & $1.74 \pm 0.68$ & $1.46 \pm 0.55 * * *$ & $1.57 \pm 0.62$ \\
\hline Sokolow-Lyon voltage index & $2.75 \pm 0.97$ & $2.49 \pm 0.80 * * *$ & $2.59 \pm 0.88$ \\
\hline
\end{tabular}

$\mathrm{SV}_{1}$, S-wave voltage in lead $\mathrm{V}_{1} ; \mathrm{RV}_{5}$, R-wave voltage in lead $\mathrm{V}_{5}$.

$* p<0.05,{ }^{*} p<0.01, * * * p<0.001$ for the comparison between men and women.

Values are means \pm SD or number of subjects (\%).

Table 2 Untreated blood pressure in 808 patients

\begin{tabular}{|c|c|c|c|c|}
\hline \multirow[t]{2}{*}{ Technique of measurement } & \multicolumn{4}{|c|}{ Mean (SD) values of blood pressure $(\mathrm{mmHg})$} \\
\hline & $\begin{array}{l}\text { Systolic } \\
\text { pressure }\end{array}$ & $\begin{array}{l}\text { Diastolic } \\
\text { pressure }\end{array}$ & $\begin{array}{l}\text { Pulse } \\
\text { pressure }\end{array}$ & $\begin{array}{l}\text { Mean } \\
\text { pressure }\end{array}$ \\
\hline $\begin{array}{l}\text { Conventional sphygmomanometry* } \\
\text { Ambulatory monitoring }\end{array}$ & $173.3(10.8)$ & $86.0(5.8)$ & $87.3(12.1)$ & $115.2(5.5)$ \\
\hline $24 \mathrm{~h}$ & $145.8(15.6)$ & $79.3(8.9)$ & $66.5(13.3)$ & $102.3(10.1)$ \\
\hline Daytime (from 10 a.m. to 8 p.m.) & $151.4(16.2)$ & $84.1(9.8)$ & $67.3(13.9)$ & $107.1(10.7)$ \\
\hline Night time (from midnight to 6 a.m.) & $134.0(18.6)$ & $70.2(10.1)$ & $63.8(14.7)$ & $92.2(11.9)$ \\
\hline
\end{tabular}

* Mean of six readings, i.e. two readings obtained at each of three run-in visits. 

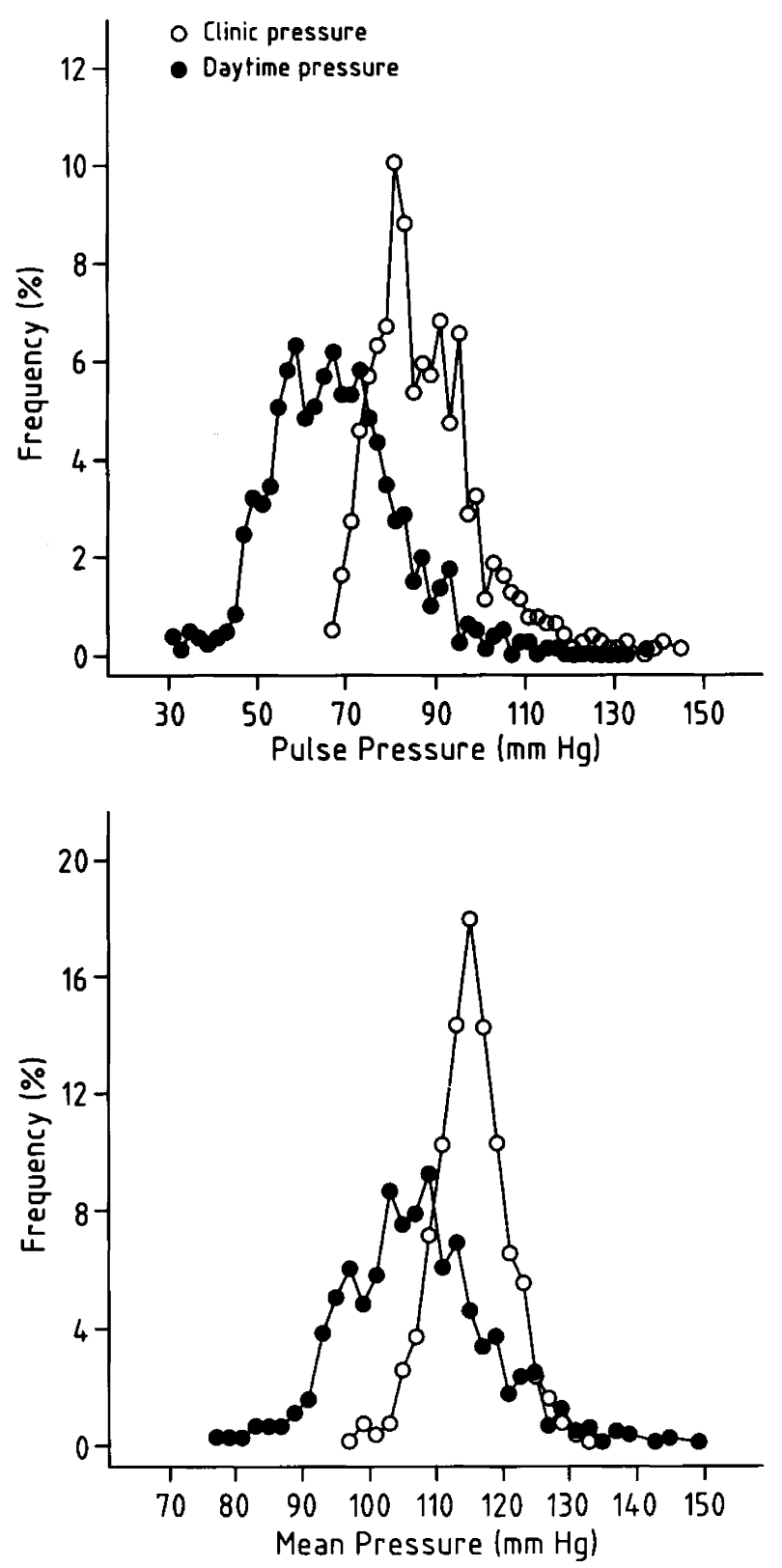

Distribution of the conventional and ambulatory pulse pressures (top panel) and mean pressures (bottom panel).

$(p<0.001)$ than the daytime ambulatory pulse pressure (Figure 1). Similarly, mean pressure was on average $8.0 \mathrm{mmHg}$ higher on conventional than on daytime ambulatory measurement (Figure 1).

\section{Correlates of pulse pressure}

In both men and women, the conventional, $24 \mathrm{~h}$, daytime and night time pulse pressures tended to increase with age. The Pearson correlation coefficients $(p<0.001)$ in the two sexes combined were $0.23,0.24$,
0.16 , and 0.28 , respectively. Pulse pressure was not related to body mass index.

\section{Correlates of Sokolow-Lyon voltage index}

The Sokolow-Lyon voltage index was $0.26 \mathrm{mV}(p<$ 0.001 ) higher in men than in women (Table 1) and decreased with age (Pearson $r=-0.08, p=0.02$ ) and body-mass index $(r=-0.18, p<0.001)$. By contrast, the Sokolow-Lyon voltage index was similar in patients who had been treated with antihypertensive drugs before enrolment and those who were not receiving antihypertensive medication $(2.58 \pm 0.90$ vs $2.59 \pm 0.87, p$ $=0.89$ ). In multiple regression analysis the SokolowLyon index was $0.21 \mathrm{mV}(p<0.001)$ higher in men than in women, decreased by $0.14 \mathrm{mV}(p=0.004)$ per decade and by $0.04 \mathrm{mV}(p<0.001)$ per $\mathrm{kg} / \mathrm{m}^{2}$ increase in body-mass index.

\section{Blood pressure as determinant of the Sokolow-Lyon voltage index}

Using multiple linear regression analysis, accounting for sex, age and body-mass index, the Sokolow-Lyon voltage index was related to blood pressure. The regression coefficients for systolic pressure were also adjusted for diastolic pressure and vice versa. Similarly, the regression coefficients for pulse pressures and mean pressures were mutually adjusted. Conventional and ambulatory systolic pressures, pulse pressures and mean pressures were significantly and positively related to the Sokolow-Lyon index, whereas the regression coefficient for the night time diastolic pressure was negative (Table 3). For a fixed level of $24 \mathrm{~h}$ mean pressure, a $10 \mathrm{mmHg}$ increase in $24 \mathrm{~h}$ pulse pressure was associated with a $0.12 \mathrm{mV}(p<0.001)$ higher Sokolow-Lyon index. Furthermore, after additional adjustment for the conventional pulse pressure, the regression coefficient for the $24 \mathrm{~h}$ pulse pressure remained statistically significant $(0.12, p<0.001)$.

Using multiple logistic regression analysis, accounting for the same covariables, the odds of having a SokolowLyon index compatible with left ventricular hypertrophy $(\geq 3.5 \mathrm{mV})$ was correlated with blood pressure. The adjusted odds ratios were significant for all types of systolic pressure and pulse pressure and for the conventional and $24 \mathrm{~h}$ mean pressures (Table 3). For a fixed level of the $24 \mathrm{~h}$ mean pressure, a $10 \mathrm{mmHg}$ increase in the $24 \mathrm{~h}$ pulse pressure increased the odds by $24 \%$ $(p=0.01)$. Furthermore, after additional adjustment for the conventional pulse pressure, the odds ratio of the $24 \mathrm{~h}$ pulse pressure remained significant $(1.21, p=$ $0.048)$.

In both the linear and logistic regression models, the slope of the relationship between the conventional and 
Table 3 Blood pressure as a determinant of the Sokolow-Lyon voltage index [17]

\begin{tabular}{|c|c|c|c|c|}
\hline & Systolic pressure & Diastolic pressure & Pulse pressure & Mean pressure \\
\hline \multicolumn{5}{|c|}{ Linear regression coefficient } \\
\hline Conventional & $0.18(0.13,0.24) * * *$ & $-0.03(-0.08,0.03)$ & $0.14(0.08,0.19) * * *$ & $0.12(0.01,0.23) *$ \\
\hline $24 \mathrm{~h}$ & $0.16(0.12,0.21) * * *$ & $-0.03(-0.07,0.01)$ & $0.12(0.08,0.17) * * *$ & $0.12(0.05,0.18) * * *$ \\
\hline Daytime & $0.13(0.08,0.17) * * *$ & $-0.02(-0.06,0.01)$ & $0.10(0.05,0.14) * * *$ & $0.09(0.03,0.15) * *$ \\
\hline Night time & $0.16(0.12,0.20) * * *$ & $-0.06(-0.10,-0.02) * *$ & $0.14(0.09,0.19) * * *$ & $0.06(0.00,0.11) *$ \\
\hline \multicolumn{5}{|c|}{$\begin{array}{l}\text { Odds ratio for Sokolow-Lyon } \\
\text { index } \geq 3.5 \mathrm{mV}[17]\end{array}$} \\
\hline Conventional & $1.50(1.27,1.78) * * *$ & $1.01(0.85,1.20)$ & $1.30(1.10,1.53) * *$ & $1.48(1.01,2.17) *$ \\
\hline $24 \mathrm{~h}$ & $1.35(1.16,1.58) * * *$ & $0.96(0.83,1.10)$ & $1.24(1.05,1.47) *$ & $1.31(1.05,1.63) *$ \\
\hline Daytime & $1.28(1.11,1.47) * * *$ & $0.94(0.83,1.07)$ & $1.21(1.04,1.41) *$ & $1.19(0.97,1.46)$ \\
\hline Night time & $1.35(1.17,1.57) * * *$ & $0.91(0.80,1.04)$ & $1.29(1.10,1.52) * *$ & $1.16(0.96,1.41)$ \\
\hline
\end{tabular}

* Regression coefficients and odds ratios were calculated for $10 \mathrm{mmHg}$ increases in systolic, mean or pulse pressures, or $5 \mathrm{mmHg}$ increase in diastolic pressure. All estimates were adjusted for sex, age and body-mass index. In addition, mutual adjustments were applied for systolic and diastolic pressures and for pulse and mean pressures.

Significance levels are indicated: $* p \leq 0.05,{ }^{*} p<0.01$ and $* * * p<0.001$.

ambulatory pulse pressure and the Sokolow-Lyon index was not different between patients who had been treated with antihypertensive drugs before enrolment and those who were not receiving antihypertensive medication in the six months preceding the placebo run-in period.

\section{Discussion}

Cross-sectional analysis of the ECG data obtained at entry in the Syst-Eur trial produced three major findings. First, electrocardiographic left ventricular mass as assessed by the Sokolow-Lyon index is better correlated with systolic than with diastolic blood pressure. Second, pulse pressure and mean pressure are independent determinants of electrocardiographic left ventricular mass in this population. Third, ambulatory blood pressure monitoring adds to the diagnostic precision of the conventional blood pressure in evaluating the severity of hypertension. Indeed, the Sokolow-Lyon index was significantly correlated with ambulatory measurements of blood pressure over and beyond the corresponding conventional clinic measurements.

The finding that systolic blood pressure was a stronger correlate of the Sokolow-Lyon voltage index than diastolic blood pressure in this elderly population is consistent with the observations of Franklin et al., who showed that, with advancing age, there was a shift from diastolic pressure to systolic pressure as predictors of coronary heart disease risk in the Framingham Heart Study [18]. In 7757 older patients ( $\geq 60$ years) with isolated systolic hypertension who had been randomized to the control groups of eight intervention trials, total mortality was positively correlated with systolic pressure at entry, whereas the association with diastolic pressure was negative [11]. Not only the age of the patients, but also the selection of the subjects on the basis of a high systolic $(\geq 160 \mathrm{mmHg}$ ) and a low diastolic $(<95 \mathrm{mmHg})$ blood pressure probably contributed to the observed closer relationship between electrocardiographic left ventricular mass and systolic as opposed to diastolic pressure.
Current guidelines for the diagnosis and management of hypertension rest almost completely on systolic and diastolic blood pressure, two specific inflection points of the blood pressure wave [19]. However, in 1989 Darne et al., [4] suggested that the blood pressure wave may be more accurately described as consisting of a steady component, mean pressure, and a pulsatile component, pulse pressure. Our finding that pulse pressure and mean pressure were independently related to the Sokolow-Lyon voltage index is in agreement with other cross-sectional studies. The Atherosclerosis Risk in Communities study showed that, after adjustment for age and body weight, electrocardiographic left ventricular mass was positively and independently correlated with greater pulse pressure and higher mean pressure [20]. In 27,687 French adults aged 40 to 69 years, both the steady and pulsatile components of blood pressure were higher in subjects with electrocardiographic evidence of left ventricular hyperthrophy than in those without hyperthrophy [4]. A case-control study of coronary heart disease showed that increased left ventricular mass was positively associated with proximal aortic stiffness [21]. In 79 normotensive subjects and 197 otherwise healthy hypertensive patients, the extent to which arterial stiffness related to echocardiographic left ventricular mass was dependent on the method by which arterial stiffness had been estimated [22]. Pressure-dependent methods showed an association with left ventricular hypertrophy, whereas the pressure-independent stiffness index $(\beta)$ and the arterial compliance index were most strongly associated with aging and left ventricular remodelling, but not hypertrophy [22].

The finding that ECG left ventricular size was significantly related to the ambulatory pulse pressure over and beyond conventional pulse pressure is in line with our previous findings that ambulatory monitoring compared to conventional blood pressure measurement, enhances the risk stratification of older patients with isolated systolic hypertension $[14,23,24]$. These observations are also consistent with the findings of Verdecchia et al., 
[25] who showed that cardiovascular morbidity in 2010 initially untreated subjects with uncomplicated essential hypertension was more closely predicted by ambulatory than by office pulse pressure even after controlling for multiple risk factors. The greater number of measurements, the absence of digit preference and observer bias, and the minimization of the white-coat effect probably contributed to these observations. In addition, the measurement technique could have played a role. Indeed the ambulatory mean pressure was directly measured by an oscillometric technique in the majority of the patients whereas the conventional mean pressure was always calculated from auscultatory blood pressure readings.

In conclusion, in older hypertensive patients pulse pressure and mean pressure are independent determinants of the Sokolow-Lyon voltage index. In addition $24 \mathrm{~h}$ ambulatory pulse pressure adds to the diagnostic precision of the conventional pulse pressure in assessing the severity of hypertension in relation to electrocardiographic left ventricular mass.

\section{Coordination and committees}

Trial coordinators

R H Fagard, J A Staessen.

Coordinators of the project on ambulatory blood pressure monitoring

D Clement, E T O'Brien, G Mancia, G Parati, J A Staessen, and L Thijs.

\section{Regional coordinators}

G G Arabidze (Bellorussia and the Russian Federation), W H Birkenhäger (The Netherlands), C J Bulpitt (United Kingdom), M Carrageta (Portugal), H Celis (Belgium), F Forette (France), J Kocemba (Poland), G Leonetti (Italy), C Nachev (Bulgaria), E T O'Brien (Ireland), E Ritz (Germany), J L Rodicio (Spain), J Rosenfeld (Israel), J Tuomilehto (Finland, Estonia and Lithuania).

\section{Steering committee}

G G Arabidze, P De Cort, R Fagard, F Forette, K Kawecka-Jaszcz, G Leonetti, G Nachev, E T O'Brien, J L Rodicio, J Rosenfeld, J Tuomilehto, J Webster, and Y Yodfat.

\section{Data monitoring committee}

C J Bulpitt, A E Fletcher, J A Staessen, and L Thijs.

\section{Endpoint committee}

P W de Leeuw, R Fagard, G Leonetti, and $\mathrm{J}$ C Petrie.

Ethics committee

W H Birkenhäger, C T Dollery, and R H Fagard.

\section{Publication committee}

W H Birkenhäger, C J Bulpitt, J A Staessen, and A Zanchetti.

\section{Coordinating Office}

N Ausloos, E Den Hond, L De Pauw, P Drent, D Emelianov, H Fan, T Kuznetsova, Y Toremans, T Nawzat, S Van Hulle, J-G Wang, and Renilde Wolfs.

Clinical Centers Participating in the Study of Ambulatory Blood Pressure Monitoring

Belgium-H Celis, R H Fagard, J A Staessen (Leuven); P De Cort (Kumtich); D Staessen, $\mathrm{J}$ A Staessen (Mechelen).

Bulgaria - S T Braianova, E G Goshev, K G Kirilov, T R Poriazova, B Shahov, V Stoyanovski (Sofia).

Estonia-T Laks (Tallinn).

Finland-M Jääskivi, C Sarti, P Tiitto-With, J Tuomilehto (Vantaa); T Hakamäki, A Lehtonen, (Turku); P Kivinen (Kuopio); E Lehtomäki (Tampere); $\mathrm{R}$ Tilvis, $\mathrm{H}$ Vanhanen, $\mathrm{K}$ Halonen (Helsinki); E Karonen (Kouvala); P S KohonenJalonen (Espoo); H Wallinheimo (Kuusankoski). Germany -S Matthias, E Ritz (Heidelberg).

Greece-A Efstratopoulos, S Voyaki (Athens).

Ireland-L Bradley, J Duggan, E T O'Brien (Dublin). Israel-C Bott-Kanner, I Kruchin, J B Rosenfeld, S Zerapha (Givataim); B Boner, J Rosenfeld, J Zabludowski (Petha Tiqva).

Italy-A Bossini, V Cagli, C Diveroli, G Germano (Rome); R Fogari, G Malamani, F Tettamanti (Pavia); M Antivalle, M Baroni, S Lattuada, F Leali, A Libretti, M Paravicini, M Rindi (Milan); E Agostinacchio, G Barracchia, A Longo, G Maiorano, E Dolce, M Merlo, R Pieri, N Pietro, A Pirrelli, V Vulpis (Bari); M Del Torre, P Palatini, E Roman (Padova); B Abdel-Haq, A Salvetti, M Simi (Pisa); M Fastidio, G Leonetti, A Ravogli, L Terzoli (Milan); A Vaccarela (Casatenovo). 
Netherlands - P de Leeuw (Maastricht), M A D H Schalekamp, A J Man in't Veld, J M J Van der Cammen, A van den Meiracker (Rotterdam); A Woittiez (Almelo).

Poland-D Czarnecka, K Kawecka-Jaszcz, M Rajzer, T Grodzicki, B Gryglewska, J Kocemba (Cracow); M Kazmirowicz, B Krupa-Wojciechowska, K Rachon (Gdansk).

Portugal-A Caetano, H Conçalves, A Costa, G Leira, A Martinez, A Mederios, S Pereira (Faro).

Slovenia-R Accetto, B Bucic, J Dobovisek, P Dolenc, B Kolsek, Z Lapanja, M Mihelic-Bricic, J Petrin, O Perc-Cercek, A Zemva (Ljubljana).

Spain-G C Barrionuevo, B Gil-Extremera, L G Gomez, J M B Garcia, A H Herrera, A MaldonadoMartin (Granada); V Cuesta, R Marin, N Navarro, F Vega (Oviedo); J Mora-Macia, J Pujadas (Barcelona); J Michauila, J Redon (Sagunto), J L Rodicio, L M Ruilope (Madrid).

United Kingdom-S G Armstrong, M Beevers (Birmingham); C Davidson, N Gainsborough, G Kingswood, G Mankikar, M O'Neal, P Sharpstone (Brighton); P Gunawardena, P J Luce, I D Starke, C J Bulpitt, T O'Brien, R Unwin, M Wilkins (London); L Gates, J C Petrie, J Webster (Aberdeen).

\section{Acknowledgements}

The Syst-Eur trial was a concerted action of the BIOMED Research Programme sponsored by the European Union. The study was carried out in consultation with the World Health Organization, the International Society of Hypertension, the European Society of Hypertension, and the World Hypertension League. The trial was sponsored by Bayer AG (Wuppertal, Germany). The Fonds voor Wetenschappelijk Onderzoek Vlaanderen (Brussels, Belgium) provided additional support. Bayer AG and Merck Sharpe and Dohme Inc (West Point, Pennsylvania, USA) donated the study medication.

\section{References}

1 Reichek N, Devereux RB. Left ventricular hypertrophy: relationship of anatomic, echocardiographic and electrocardiographic findings. Circulation 1981; 63:1391-1398.

2 Savage DD, Garrison RJ, Kannel WB, Anderson SJ, Feinleib M. Considerations in the use of echocardiography in epidemiology: The Framingham Study. Hypertension 1987; 9 (Suppl 2):40-44.

3 Levy D, Labib SB, Anderson KM, Christiansen JC, Kannel WB, Castelli WP. Determinants of sensitivity and specificity of electrocardiographic criteria for left ventricular hypertrophy. Circulation 1990; 81:815-820.

4 Darne B, Girerd X, Safar M, Cambien F, Guize L. Pulsatile versus steady component of blood pressure: a cross-sectional analysis and a prospective analysis on cardiovascular mortality. Hypertension 1989; 13:392-400.

5 Rutan GH, Kuller LH, Neaton JD, Wentworth DN, McDonald RH, McFate Smith W. Mortality associated with diastolic hypertension and isolated systolic hypertension among men screened for the Multiple Risk Factor Intervention Trial. Circulation 1988; 77:504-514.
6 Madhavan S, Ooi WL, Cohen $\mathrm{H}$, Alderman $\mathrm{MH}$. Relation of pulse pressure and blood pressure reduction to the incidence of myocardial infarction. Hypertension 1994; 23:395-401.

7 Mitchel GF, Moyé LA, Braunwald E, Rouleau JL, Bernstein V, Geltman $\mathrm{EM}$, et al. Sphygmomanometrically determined pulse pressure is a powerful independent predictor of recurrent events after myocardial infarction in patients with impaired left ventricular function. Circulation 1997; 96:4254-4260.

8 Millar JA, Lever AF, Burke V. Pulse pressure as a risk factor for cardiovascular events in the MRC Mild Hypertension Trial. J Hypertens 1999; 17:1065-1072.

9 Franklin SS, Khan SA, Wong ND, Larson MG, Levy D. Is pulse pressure useful in predicting risk for coronary heart disease? The Framingham Heart Study. Circulation 1999; 100:354-360.

10 Blacher J, Staessen JA, Girerd X, Gasowski J, Thijs L, Liu L, et al. Pulse pressure, not mean pressure determines cardiovascular risk in older hypertensive patients. Arch Intern Med 2000; 160:1085-1089.

11 Staessen JA, Gasowski J, Wang JG, Thijs L, Den Hond E, Boissel JP, et al. Risks of untreated and treated isolated systolic hypertension in the elderly: meta-analysis of outcome trials. Lancet 2000; 355:865872.

12 Emelianov D, Thijs L, Staessen JA, Celis H, Clement D, Davidson C, et al. Conventional and ambulatory blood pressure measurement in older patients with isolated systolic hypertension: baseline observations in the Syst-Eur trial. Blood Press Monit 1998; 3:173-180.

13 Staessen JA, Fagard R, Thijs L, Celis H, Arabidze GG, Birkenhäger $\mathrm{WH}$, et al. Randomized double-blind comparison of placebo and active treatment for older patients with isolated systolic hypertension [correction published in Lancet 1997, volume 350, November 29, p 1636]. Lancet 1997; 350:757-764.

14 Staessen JA, Thijs L, Fagard R, O'Brien ET, Clement D, de Leeuw PW, et al. Predicting cardiovascular risk using conventional and ambulatory blood pressure in older patients with systolic hypertension. JAMA 1999; 282:539-546.

15 Weber MA. The measurement of arterial properties in hypertension. Am $J$ Hypertens 2001; 14:183-185.

16 Prineas RJ, Crow RS, Blackburn H. The Minnesota Code Manual of Electrocardiographic Findings - Standards and Procedures for Measurement and Classification. Littleton, Massachusetts, USA. John Wright PSG Inc; 1982.

17 Sokolow M, Lyon TP. The ventricular complex in left ventricular hypertrophy as obtained by unipolar precordial and limb leads. Am Heart $J$ 1949; 37:161-186.

18 Franklin SS, Larson MG, Khan SA, Wong ND, Leip EP, Kannel WB, et al. Does the relation of blood pressure to coronary heart disease change with aging? The Framingham Heart Study. Circulation 2001; 103:1245-1249.

19 The Joint National Committee on Prevention Detection Evaluation and Treatment of High Blood Pressure. The sixth report of the Joint National Committee on prevention, detection, evaluation, and treatment of high blood pressure (JNC VI). Arch Intern Med 1997; 157:2413-2446.

20 Arnett DK, Rautaharju P, Crow R, Folsom AR, Ekelund LG, Hutchinson $\mathrm{R}$, et al. Black-white differences in electrocardiographic left ventricular mass and its association with blood pressure (the ARIC Study). Am J Cardiol 1994; 74:247-252.

21 Gatzka CD, Cameron JD, Kingwell BA, Dart AM. Relation between coronary artery disease, aortic stiffness, and left ventricular structure in a population sample. Hypertension 1998; 32:575-578.

22 Roman MJ, Ganau A, Saba PS, Pini R, Pickering TG, Devereux RB. Impact of arterial stiffening on left ventricular structure. Hypertension 2000; 36:489-494.

23 Cox J, Amery A, Clement D, De Cort P, Fagard R, Fowler G, et al. Relationship between blood pressure measured in the clinic and by ambulatory monitoring and left ventricular size as measured by electrocardiogram in elderly patients with isolated systolic hypertension. J Hypertens 1993; 11:269-276.

24 Fagard RH, Staessen JA, Thijs L, Gasowski J, Bulpitt CJ, Clement D, et al. Response to antihypertensive therapy in older patients with sustained and non-sustained systolic hypertension. Circulation 2000; 102:1139-1144.

25 Verdecchia P, Schillaci G, Borgioni C, Ciucci A, Pede S, Porcellati C. Ambulatory pulse pressure. A potent predictor of total cardiovascular risk in hypertension. Hypertension 1998; 32:983-988. 